\title{
Son Preference in India: Shedding Light on the North-South Gradient
}

\author{
Daniela Klaus, Arun Tipandjan
}

\begin{abstract}
Son preference is widespread in India and deep-rooted in its history. It is a matter of concern because it produces an imbalanced juvenile sex ratio. There are far fewer girls than boys. The figures vary greatly among the Indian states suggesting a major north-south gradient in son preference accompanied by a minor westeast gradient. The aim of this paper is to explain the regional pattern. We provide an application of the value of children-approach according to which the decision to have children is made on the calculus of benefits and costs related to children. In the light of the socioeconomic and sociocultural background in India, we propose that (potential) parents' expectations of benefits and costs are biased in favour of sons. This is suggested, therefore, as the key motivation for the preference for male offspring. However, region-specifics in the level of affluence, the educational level, the mode of production, the meaning and importance of religion, and the kinship regime are assumed to produce stronger son preference in north India compared to south India. This mediation-model is tested using the Indian sub-sample of the international Value of Children-study. Data were collected in Uttar Pradesh (northcentral India) and Puducherry (south-east India). Mothers aged 16 to 65 were interviewed in 2002 and 2010. Based on 1,173 respondents, a structural equation model was carried out to test the hypothesised composition effects related to the region and the mediating position of sex-specific benefits and costs. Initial findings confirm that the national son preference pattern is more likely to be found among north Indian mothers than south Indian mothers. As assumed, the sex-specific balance of benefits and costs contributes to the explanation of son preference. However, there is little evidence that the benefits and costs mediate between the region-specific socioeconomic and sociocultural profiles and son preference. Son preference is most pronounced among mothers of the north-urban sample after controlling for region-specific distributions of socioeconomic and sociocultural background variables. Variations in son preference across the regional sub-samples are partly explained by the respective background variables and the benefit and cost-structure. But independent regional effects continue to be significant and thus, a considerable part of the north-south gradient remains unclear.
\end{abstract}

Keywords: Son preference $\cdot$ India $\cdot$ Value of children $\cdot$ Kinship regime $\cdot$ Dowry 


\section{Introduction}

Son preference is widespread in India and deep-rooted in its history. Although it is common in the Middle East, North Africa, and in South and East Asia, it is most pronounced in India and China. There is great public concern about this issue for at least two reasons: First, it is widely argued that son preference is slowing the transition to low levels of fertility as couples might continue to bear children until the desired number of sons is reached. But empirical evidence is mixed and suggests a complex interplay (Arnold et al. 1998; Basu 1999; Bhat/Zavier 2003; Clark 2000; Das Gupta/Bhat 1997; Mutharayappa et al. 1997; Pande 2003; Srinivasan 2005). The spread of the preference for smaller families might add to the pressure to prevent the birth of daughters because the probability of having a son decreases with the lower overall number of preferred children (UNFPA 2012: 42-43)

Second, son preference implies gender discrimination which is manifested in a broad range of sex-selective behaviour (Basu 1999; Behrman 1988; Borooah 2004; Das Gupta/Bhat 1997; Oster 2009; Pande 2003; Pande/Astone 2007; Rosenzweig/ Schultz 1982; Sengupta/Agree 2002; Srinivasan 2005): Sex-selective investments in education, autonomy, and self-determination reproduce the subordinate social and economic position of women. Sex-selective rates of abortion and infanticide and sex-specific health care and nutrition produce sex-selective mortality and thus distorted sex ratios. India, like some other Asian countries, faces the problem of "missing women" (Sen 2005: 225) which implies, among other things, a shortage of women on the marriage market - termed a "marriage squeeze". Within the last decades, the juvenile sex ratio, defined as the number of boys aged 0 to 6 per 100 girls of the same age, became increasingly disproportional: It has increased from 102 in the middle of the $20^{\text {th }}$ century to 110 in 2011 with an accelerated increase in the 1980s (Bhaumik 2012). This rise does not indicate an intensification of the son preference but its stronger manifestation, supported by the growing availability of methods of sex diagnosis technology. The development of prenatal diagnostics is the driving factor behind the shift from the traditional postnatal discrimination to the more effective practice of female abortion (Goodkind 1996). A harmful side effect of such a rigid avoidance of giving birth to a female child may be the impairment of women's mental and physical health due to (multiple) abortions.

The alarming development of the sex ratio in India can largely be attributed to the north-western states. Latest figures for the juvenile sex ratio suggest a major north-south gradient which is accompanied by a minor west-east gradient. Apart from few exceptions, states in the northern plains and in the central upland show ratios that are well above 110. Ratios in south-east India reach around 105. In some selected states like Kerala and Puducherry they are almost balanced (Bhaumik 2012; Government of India 2011; UNFPA 2012). This uneven distribution of the sex ratio across the regions is accompanied by a similar distribution of son preference (Bhat/ Zavier 2003: 639, 644; International Institute for Population Sciences (IIPS)/Macro International 2007: 106). In fact, the alleged north-south divide is an imprecise reflection of India's diversity which needs to be refined: Son preference is prevalent in 
north-west India and is less common in south-east India. For reasons of simplification, we talk about north-south differences in the following.

The aim of this paper is to contribute to the explanation of this regional pattern, which in turn implies understanding the rationale behind the son preference. We apply the revised value of children (VOC)-approach (Nauck 2001) which is grounded in the rational choice tradition. Accordingly, we argue that gender bias is caused by the sex-specific expectations of benefits and costs on the part of (potential) parents. These child-related expectations arise from the respective mix of parents' socioeconomic characteristics and the cultural setting in which they live. Prominent regional variations in these background variables imply a favourable cost-benefit balance of sons compared to daughters in north India. We test the developed theoretical model using data from the international Value of Children-replication study (Trommsdorff) Nauck 2005). We use a sample of 1,173 mothers collected in the north-central Indian state of Uttar Pradesh in 2002 and in Puducherry, which is located on the east coast in south India in 2010. Son preference is captured by an attitudinal measure. Since the study neglects the male perspective, the prevalence of son preference may be underrated but the interrelations between the explanatory variables and the outcome should not be biased.

The remainder of our article is organised as follows: In the next section, the theoretical model is outlined. Its major implications are discussed in the light of the research on son preference in India in section three. This is followed by a sketch of the theoretical model and the presentation of the hypotheses. Section five provides the data and measures employed for the analyses. Findings are shown in section six and are discussed in the final conclusion.

\section{Theoretical Background: The Value of Children-Approach}

Numerous studies are dedicated to son preference in India but most of them focus on its drastic consequences for society in general, and for girls and women in particular. Much less research explores son preference as an outcome. The few exceptional studies conclude that son preference is deeply entrenched in India's economic, social, and religious structure (Chamarbagwala 2011; Das Gupta et al. 2003; Diamond-Smith et al. 2008; Dyson/Moore 1983; Gaudin 2011; Nasir/Kalla 2006; Pande/Astone 2007; Probst 2009; UNFPA 2012; Vlasoff 1990). More precisely, the sexspecific value of children in India stems from widespread agricultural (wheat) production, the great importance of religion, the persistence of the caste system, the patrilineal and patriarchal organisation of society and the related custom of dowry. Yet a theoretically driven and stringent conceptualisation which relates significant background characteristics, child related benefits and costs, and the corresponding sex bias, is rarely provided. Moreover, previous empirical work did not aim at disentangling the explanatory power of the socioeconomic and cultural variables stressed (except the study by Pande/Astone 2007) and also omitted quantifying the sex-specific benefits and costs. 
To fill the theoretical gap, we apply the revised (VOC)-approach (Nauck 2001). Some theoretical traditions argue that the decision on the number of children is made on the calculus of child-related benefits and costs (Becker 1996; Friedman et al. 2007; Leibenstein 1975; Liefbroer 2005). So does the VOC-approach. It is built on the idea that individuals strive to optimise their wellbeing. For this purpose they invest in their personal resources like educational attainment, money, professional career, leisure time activities, or in social relationships such as the relationship to offspring. Relying on the theory of social production functions (Ormel et al. 1999) the value of children comprises children's potential to provide comfort, social esteem, and affection as main aspects of wellbeing. This analytical distinction basically matches what the initial value of children research calls the economic, the socialnormative, and the emotional value of children (e.g., Arnold et al. 1998; Kagitcibasi 1982). In addition to the benefit-side, direct and (indirect) opportunity costs arising from child-rearing are taken into account. The degree to which children are linked to benefits and costs depends on the characteristics and resources of the (potential) parents as well as the contextual setting in which they are embedded. It is argued that child-related preferences and fertility behaviour are determined by the childrelated benefits and costs. Even though relying on this rationale we are aware of the individual's bounded rationality (Simon 1982) as we assume a subjective perception of costs and benefits based on incomplete information.

The VOC-approach has been successfully applied to explain cross-national variations in fertility rates (e.g., Nauck 2007) and the historical decline in fertility (e.g., Klaus 2010). Because it is reasonable to assume that boys and girls differ in their benefits and costs in many countries worldwide, it seems to be promising to adopt this approach for the investigation of sex preference. Thus, in this paper, we follow the theoretical proposition of the VOC-approach and the corresponding view formulated elsewhere: "The calculus of preferences for children of a particular sex can be understood by extending the concept of the value of children to the two sexes separately. If the net utility of having a son outweighs that of having a daughter, parents are likely to prefer sons to daughters. A complex interplay of economic and sociocultural factors determines the benefits and costs of a child" (Arnold et al. 1998: 301).

\section{The Value of Sons and Daughters in India}

Against India's socioeconomic and sociocultural background, existing studies emphasise the children's economic-instrumental value, the marriage transaction costs due to the custom of dowry payment, and children's social-normative value rooted in the dominant patrilineal kinship system and traditional beliefs (e.g., Arnold et al. 1998; Vlasoff 1990). We observe a widespread consensus that daughters are less valuable to parents than sons. Moreover, a strong socially and economically motivated pressure to bear at least one son and to limit the number of girls is emphasised. In the following, the relevant research literature is reviewed in the light of 
the VOC-propositions. The focus will be on potential inter-individual variations and variations across regions.

\subsection{The Economic-Instrumental Benefit of Children}

Agriculture still plays an important role in India's economy. Today the agricultural sector contributes to only around 17 percent of the gross domestic product of India (Reserve Bank of India 2012: Table 3) but engages around half of the country's manpower. Strong dependence of agrarian production on the climate and the weather implies an economically hazardous environment for a large part of the population. This is aggravated by the overall lack of public old age security and other insurance schemes covering the risks of life. As a consequence and in line with the key propositions of the VOC-approach, economic incentives to have children are prevalent in India.

However, the economic-instrumental utility flow is usually in favour of sons (e.g., Cain 1986; Chen et al. 2011; Probst 2009; Vlasoff 1990) for at least two reasons: First, India is a patrilineal society in which patrilocal household formation is inherent (e.g., Dyson/Moore 1983; Singh 2005). Daughters are absorbed into their husband's line once they are married. Although very valuable for their husbands' family, women are of limited long-term value for their own parents. Usually the son and his family of procreation are obliged to take care of his elderly and frail parents. Second, the son's responsibility is accompanied by his higher productive potential. Having a son means a reliable source of labour in farming where manual labour is still important despite the growing spread of modern technology. Men also have greater opportunities for gainful employment since they are higher educated and qualified than women, who have gained in education and paid labour participation within the recent decades but "are still not encouraged to work outside the home" due to persisting patriarchal norms which restrict their presence in the public sphere (Singh 2005: 150). Men's superior economic status is reinforced by the dominance of patrilineal inheritance rules which ensure their ownership of productive assets like the land, farm, or the family business.

Nevertheless, regional variations can be assumed, first of all, due to the varying strength of the patrilineal kinship regime across the country. In their seminal work Dyson and Moore (1993, see also Das Gupta et al. 2003) identified two systems that meet in India and which are part of larger sociocultural areas. The north Indian system as part of the West Asian model is very rigid as patrilineality is the rule and thus, prevailing gender discrimination is reinforced. Daughters are largely seen as an economic drain on their families. This differs from the south Indian system, which belongs to the South and East Asian kinship model. Here, the logic of patrilineality is still dominating but is more flexible. Endogamy is practiced which refers to the custom to marry within a certain (social) group similar to that of the own family. The newly married couple usually reside separately from the husband's family (neolocality) which enables daughters to remain (physically) close to their parents after their marriage. Women may inherit and transfer property rights (Agarwal 1988). As a consequence both sons and daughters might render help for their families 
and parents in south India. This coincides with women's higher contribution to the family subsistence in the rice-growing agriculture which dominates in south India. Women play a major role in the rice-production from weeding to harvesting. Thus, they are of relatively high economic value in contrast to central and north India where wheat production is widespread (Reserve Bank of India 2012: Table 23) and basically requires male "muscle power" (Pande/Astone 2007: 5).

Economic prosperity and educational attainment are also argued to contribute to a smaller gender gap because of a lower overall economic-instrumental benefit of children. Parents gain financial independence from their offspring if their socioeconomic resources increase. On the other hand, impoverished households and low educated segments of the population depend on (minor) children's contribution to the family's living. In this respect, again, noteworthy regional differences can be observed. In the southern states (as well as a few states in northernmost India) a great part of the population can read and write (around 80 percent) whereas literacy is much lower in the states of the northern central upland (Government of India 2011). A similar pattern is found for affluence: The north-central strip of India exhibits the lowest gross domestic product, embracing Uttar Pradesh with 1,586 USD per capita in 2009. This contrasts with the much higher GDP in south India, which amounted to up to 6,602 USD in Puducherry in 2009, for instance (The Economist 2012).

To summarise, the widespread gender gap in terms of the economic-instrumental benefit is assumed to be smaller in south India. Here we observe a unique setting where attenuated patrilineality, rice production, and trends of economic prosperity and educational expansion converge.

\subsection{The High-Cost Custom of Dowry}

The majority of child-related costs are of a financial nature. This comprises expenditures for children's upbringing (nutrition, investments in health care), their education and their marriage (direct costs) but also covers the loss of a mother's contribution to the household's subsidence or income when she takes care of her children (indirect costs). Whereas the latter is assumed to be of the same value regardless of the child's sex, higher investments into (the income potential of) sons may cause higher son-related direct costs. This sex-related ratio, however, might be reversed if marriage transaction costs are taken into account. Whereas the practice of a bride price raised by the husband's family dominates worldwide, India is one of the few societies to feature the payment of a dowry. Dowries entail a transfer from the bride's family to the groom and his family at the time of marriage. Studies widely agree that the custom of dowry is a key issue in the understanding of the persistent son preference in India (e.g., Diamond-Smith et al. 2008; Jaggi 2001).

In the literature, several interrelated reasons are discussed that may account for the existence of dowry (e.g., Dalmia/Lawrence 2005). It is common where women's productive input to the household is low and where patrilineal and patriarchal structures prevail (Dyson/Moore 1983; Jejeebhoy/Sathar 2001; Singh 2005). The dowry payment aims at maintaining the status of the bride's family since it is considered as a symbol of prestige. Its absolute amount "increase[s] with both the wealth and 
social status of both sides of the marriage bargain" (Anderson 2007: 163). Moreover, high dowry payments are a strategy for social upward mobility. This is related to the caste-based structure of India which implies that social status is independent of financial capital and is inherited through caste. This motivates hypergamy, i.e. the marriage to a husband of a higher status than the bride's family.

High dowry payments used to be an upper class phenomenon but have been increasingly adopted by lower status and low caste families within the last decades (Miller 1981; Singh 2005). This trend might be triggered by the growing affluence and welfare dispersion among the Indian population which has enabled a growing share to make use of dowry as a means of increasing status and a rise in family's prestige (Anderson 2003). Even in traditional bride-price regions in south India like Tamil Nadu, a spread of dowry has been observed (Anderson 2003; Caldwell et al. 1982; Rao 1993; Singh 2005). Since in south India the preference for one child of each sex is common due to the high benefits attached to boys and girls, the growing practice of dowry started to raise concern among families about the immense financial pressures, at least after having two daughters (Diamond-Smith et al. 2008: 697). To summarise, dowry is mandatory in north India and rural areas due to stronger patrilineality and stronger patriarchial norms and payments are argued to be highest among the upper class.

\subsection{The Social-Normative Benefit of Children}

Depending on the social and cultural context in which the family is embedded, children enhance parent's status attainment (Nauck 2007: 617). In social structures where the continuance of the lineage is a highly salient goal, the birth of a child increases the parental status and provides behavioural confirmation. In patrilineal societies like India, only male offspring can carry on the family name, continue the family line and therefore, reproduce the family's social status. Moreover, religious customs and traditions in India bear a high religious bias towards sons. A son provides prestige not only during parents' lifetime but above all, after their death (Caldwell et al. 1984; Das Gupta et al. 2003; Probst 2009; Vlasoff 1990). For Hindus, who make up the majority of Indians (81 percent), having a son is imperative (Singh 2005: 131). He is the only one who can light the funeral pyre of his deceased parents, offer ancestral worship and thus ensure the salvation of their souls. Therefore, in terms of the social-normative value of children, the sex gap is most evident. But since patrilineality and the aim to achieve immortality are most prominent in northwest India (Das Gupta et al. 2003), the social-normative value of sons should be more pronounced here than in south India.

To sum up, there is strong evidence that the cost-benefit balance of children is generally in favour of sons and it is argued that this is the main reason for a widespread son preference. Nevertheless, regional differentials can be expected which come into effect due to region-specifics in terms of the kinship regime, the significance of religiosity, and the socioeconomic profile of the inhabitants. The access to (higher) education and monetary resources as well as sociocultural identity depend on the individual's place of residence. 


\section{$4 \quad$ Theoretical Model and Hypotheses}

Figure 1 provides a sketch of our theoretical model. Whether sons or daughters are preferred or no preference at all exists depends on the respective combination of sex-specific benefits and costs attached to children by their (potential) parents. The cost-benefit structure is, however, not arbitrary but a result of the individual's socioeconomic status and its sociocultural embedding - both systematically varying across regions. The review provided has exposed the educational and the welfare levels as meaningful facets of individual's socioeconomic status. The strength of patrilineality and the magnitude of religiosity are found to be the most relevant factors characterising the individual sociocultural background.

Fig. 1: Theoretical model

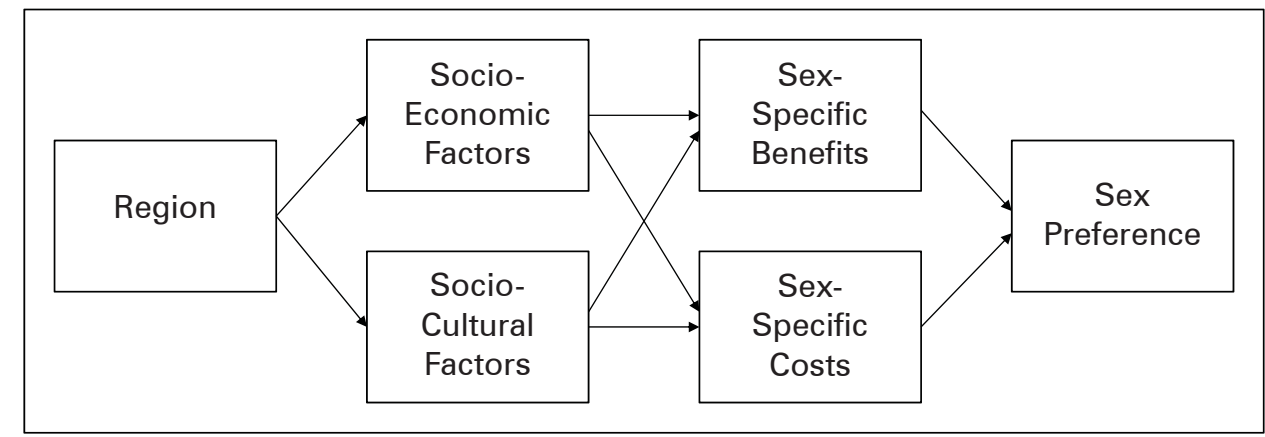

Source: Own design

The model suggests a complex path dependency of our major outcome variable. The explanation of son preference in India includes the aim of shedding light on regional variations by means of the explanatory components in between. This implies a multiple mediator model as illustrated in Figure 1. A set of subsequent hypotheses can be derived.

As a starting point, we assume regional variations in the prevalence of son preference.

(H1) Son preference is more prevalent in north India than south India.

$(\mathrm{H} 2)$ The regional variations in son preference are mediated by individual characteristics rather than being independent (mediation effect).

The mediation is assumed to be based on multiple mediators. First of all, regions differ in terms of socioeconomic and sociocultural characteristics (composition effects).

(H3) The socioeconomic status is higher in south India than north India.

$(\mathrm{H} 4)$ Patrilineality and religiosity are stronger in north India than south India.

The benefits and costs related to sons and daughters are the core of the mediation. They are assumed to depend on the individual's background variables and, at the same time, to predict the son preference directly (benefit-cost effects). 
(H5) Son preference is more likely the higher the relative benefits related to sons.

(H6) Son preference is more likely the higher the relative costs related to daughters.

(H7) The higher the socioeconomic status, the lower the relative benefits related to sons.

(H8) The higher the socioeconomic status, the higher the relative costs related to daughters.

(H9) The higher the level of patrilineality and religiosity, the greater the costbenefit structure of children in favour of sons.

\section{$5 \quad$ Method}

\subsection{Data}

Analyses were made using data from the international Value of Children-replication study (Trommsdorff/Nauck 2010; Trommsdorff/Nauck 2005). Data were collected in 17 countries worldwide. Within this research program, an Indian sub-sample was realised in two geographical areas that are prototypical for north and south-east India in respect of our outcome and the potential predictor variables. In 2002, the north Indian sample was carried out in the state of Uttar Pradesh which is located in the central upland. Interviews were conducted in Varanasi City and in several villages of the Naugarh Block of the Chandauli district. In 2010 a south Indian sample was realised at the south-east coast inside the state of Tamil Nadu. An urban sample was conducted in the city of Puducherry and a rural sample in some villages nearby in the districts Villupuram and Cuddalore. The 8-year gap in fieldwork might produce biased findings with respect to the prevalence of son preference. An underestimation of the gap between the north and south Indian sample can be expected since the juvenile sex ratio has slightly increased between 2001 and 2011 in Uttar Pradesh but not in Tamil Nadu (Government of India 2011). Nevertheless, the bias should be small and regression coefficients are not affected. Respondents were interviewed face-to-face with a standardised questionnaire. The questionnaires were available in Hindi (north India) and Tamil (south India).

In fact, the study has realised a three-generation sample design of mothers, grandmothers and adolescents. For the present analysis we have selected the subsample of mothers. Fathers were not included in this study. Convenience sampling method was applied: Mothers were recruited in institutions like schools, kindergartens, and self-help groups. Rural families were approached directly in their homes. Altogether 1,173 valid interviews are available that are equally distributed over four regions we differentiate in order to capture the hypothesised north-south gradient but also to control for possible urban-rural differences: north-rural, north-urban, south-rural, and south-urban. The surveyed mothers are in different stages of their life: They are aged between 16 and 65 years with an average age of 32 years. Mothers in north India are somewhat older ( rural $=33$; urban $=35$ ) than their southern counterparts (rural $=32$; urban $=33$ ). This corresponds to the higher number of 
children in the north Indian sample (rural $=3.0$; urban $=2.3$ ) compared to the south Indian sample (rural $=2.0$; urban $=2.0$ ).

\subsection{Measures}

Son preference is covered by an attitudinal indicator. Respondents were asked for their sex preference: "If you had exactly one child, would you prefer it to be a boy or a girl or is it all the same to you?" A more implicit measuring was realised in the Indian National Family Health Survey (NFHS) where sex preference was assessed by asking for the ideal number of children and its distribution on both sexes (International Institute for Population Sciences (IIPS)/Macro International 2007: 103). The forced choice questioning applied here may provoke higher rates of hidden sex preference but obviously does not as demonstrated later (Fig. 2). Overall, the majority state no preference (75 percent). Apart from that, son preference is more prevalent (20 percent) than daughter preference ( 6 percent). To mitigate adverse consequences of a potential answer bias due to the fact of varying sex-compositions of children already born to the respondent, the number of sons is included as control variable (Gaudin 2011). For the multivariate analysis the indicator is dichotomised: son preference (score 1) versus daughter or no preference (score 0 ).

The sex-specific costs of children are measured by a single question asking: "Who costs the most financially: sons or daughters or do they cost about the same?" Corresponding to the distribution of the sex preference, the share of those who declare that child's sex does not matter in terms of expenditures is highest (71 percent). Only 6 percent of the respondents assess sons to be more expensive and 23 percent vice versa. Again, the categorical variable is recoded into a dummy indicator with score 1 indicating relative higher costs attached to daughters.

Two scales are available asking for the benefits expected from grown-up daughters and grown-up sons. Among others, they cover instrumental and financial aspects by two items which refer to care in old age and financial assistance provided by the adult child. Respondents rated them using a response-scale ranging from "not very important" (score 1) to "very important" (score 5). Both items are significantly interrelated $(p<0.01)$ which applies with respect to sons $(r=0.56)$ and with respect to daughters $(r=0.45)$. They were summed separately for daughters and sons. To obtain a measure of the relative benefit expectations, both sex-specific scores were subtracted and then respondents were classified: Mothers with a value within the range of one standard deviation were assigned to the group with no sex-specific benefits. They have provided nearly the same level of benefit-expectations towards daughters and sons. Again, this applies to the majority of our sample (55 percent). Mothers beyond one standard deviation were classified either as higher daughter-benefits (10 percent) or as higher son-benefits (34 percent). In our multivariate model higher son-benefits (score 1 ) are contrasted to any other expectations (score 0 ).

The benefit indicator just presented is restricted in two ways: Expectations towards minor children are not covered nor are social-normative benefits. The first issue is less harmful as the relevant sex gap in instrumental and financial terms 
only starts to widen when children marry. Thus, the focus on long-term benefits should cover a large part of the expected sex differences. The second objection is more precarious because the gendered social-normative benefits are assumed to account for the son preference to a great deal. To alleviate this weakness, we rely on another scale asking for a number of reasons for having children. The item "a duty according to belief" is employed as a proxy to capture a son's relevance to carry on the family name and maintain parents' afterlife. The same five-point response scale is used as for the sex-specific benefits. The overall mean score amounts up to 2.7 $(\mathrm{SD}=1.50)$.

The respondent's socioeconomic position is captured by two indicators: the household's welfare level and the educational level of the surveyed mother. The welfare is measured by a cumulative count of the actual property held by the household in which the respondent lives. It covers a summer house, gold, jewellery, stocks, and car. Home ownership and the holding of a plot of land were intentionally excluded. They are the rule for the rural population and we suspect them to be an indication of production means and the rural mode of living rather than a measure of affluence. On average, households possess one of the five items $(M=0.9$; $S D=1.12)$.

Education comprises four groups. The group of respondents with no degree (score 0 ) is the largest (32 percent). Respondents who have completed primary (score 1) and secondary school (score 2) are found in equal shares: 26 percent. The remaining 17 percent of respondents have a tertiary degree. Assuming that respondents can convert their education into a corresponding career and salary, this indicator provides approximate information about their wage potential and thus, their dependency on children's financial support.

The sociocultural setting is described by patrilineality and religiosity. An attempt to measure the flexibility of the patrilineal rules was made by using the respondent's contact pattern to the affinal (husband's) kin in relation to the consanguineous (own lineage's) kin. The data provide the contact frequency for the oldest brother, the oldest sister, the mother, the father and the four in-law pendants. Contact comprises face-to-face contact and contact mediated by letter, email, and phone. A five-point answer scale was applied ranging from "daily" (score 1) to "less than once a month" (score 5). Separately for every four positions, a relative contact rate was computed. A positive score indicates more frequent contact with the affinal family member and a negative score indicates more contact with the consanguineous family member. The four single indicators were then aggregated by computing an average score. This final indicator stretches from "low flexibility of patrilineal rules" (score +4$)$ to "high flexibility of patrilineal rules" (score -4). The score zero indicates a balanced contact rate to the members of both lineages. Overall, respondents tend to pronounced patrilineality ( $M=1.0 ; S D=1.81)$.

Nearly all of our respondents are affiliated to Hinduism (96 percent). Regardless of their belief, they were asked to rate how important their religion is to them on a five-point scale ranging from "not important at all" (score 0) to "very important" (score 4). The mean value proves a very high level of religiosity for our sample $(\mathrm{M}=3.4 ; \mathrm{SD}=0.79)$. 
To control for the different stages of life in which respondents were surveyed and for the diverse experiences they have with sons, we include in the analysis the respondent's age (range $=16-65 ; \mathrm{M}=33 ; \mathrm{SD}=8.06$ ) and the number of sons born (range $=0-8 ; \mathrm{M}=1.2 ; \mathrm{SD}=0.99$ ).

\subsection{Analytical Approach}

Structural equation modelling (SEM), specifically path analysis, is applied to test for the hypothesised composition effects related to the respondent's regional location as well as to test for the suggested mediating position of the cost- and benefitstructure. Direct and indirect effects are computed simultaneously and the sobeltest (z-score) is provided to test for the statistical significance of the indirect effects. Weighted least square estimations (WLSMV) are carried out to account for the combination of binary and continuous indicators. Linear regressions are obtained in case of continuous dependent variables and probit regressions are obtained in case of binary dependent variables. Basically, standardised probit coefficients can be interpreted much the same way as OLS-regression coefficients. Positive coefficients indicate positive effects of the predictor variable on the outcome and vice versa.

\section{$6 \quad$ Results}

\subsection{Bivariate Findings}

Figure 2 illustrates differences in the sex preference across the regions. As hypothesised $(\mathrm{H} 1)$, the percentage of mothers who state a preference for a son is significantly higher in the north Indian sample (32 percent in the rural and the urban sample) compared to the south Indian sample ( 7 percent in the rural and 6 percent in the urban sample). Apparently, sex preference is the exception in south India: For a great majority of respondents, having a son or a daughter is all the same (82 percent in the rural and 88 percent in the urban sample). In fact, having no preference dominates throughout our sample, which contradicts the widespread view of a common son preference in India. This may result from the sample selection (mothers in two selected areas of India) and the use of an attitudinal measurement of sex preference instead of using a behavioural outcome. Using a similar measurement, the Indian NFHS reports very similar distributions for Uttar Pradesh and Tamil Nadu which promotes our results (International Institute for Population Sciences (IIPS)/Macro International 2007: 106).

At the same time, this finding may also indicate (the onset of) a change toward greater gender equality starting with changing attitudes. It is also noteworthy that only a few more southern respondents prefer a daughter to a son compared to their northern counterparts and the likelihood for son preference does not vary between urban and rural mothers, neither in north nor in south India.

At this aggregate-level, the region-specific pattern of sex preference revealed corresponds to the regional cost- and benefit-structure in the way we have pro- 
Fig. 2: Region-specific sex preference (in percent)

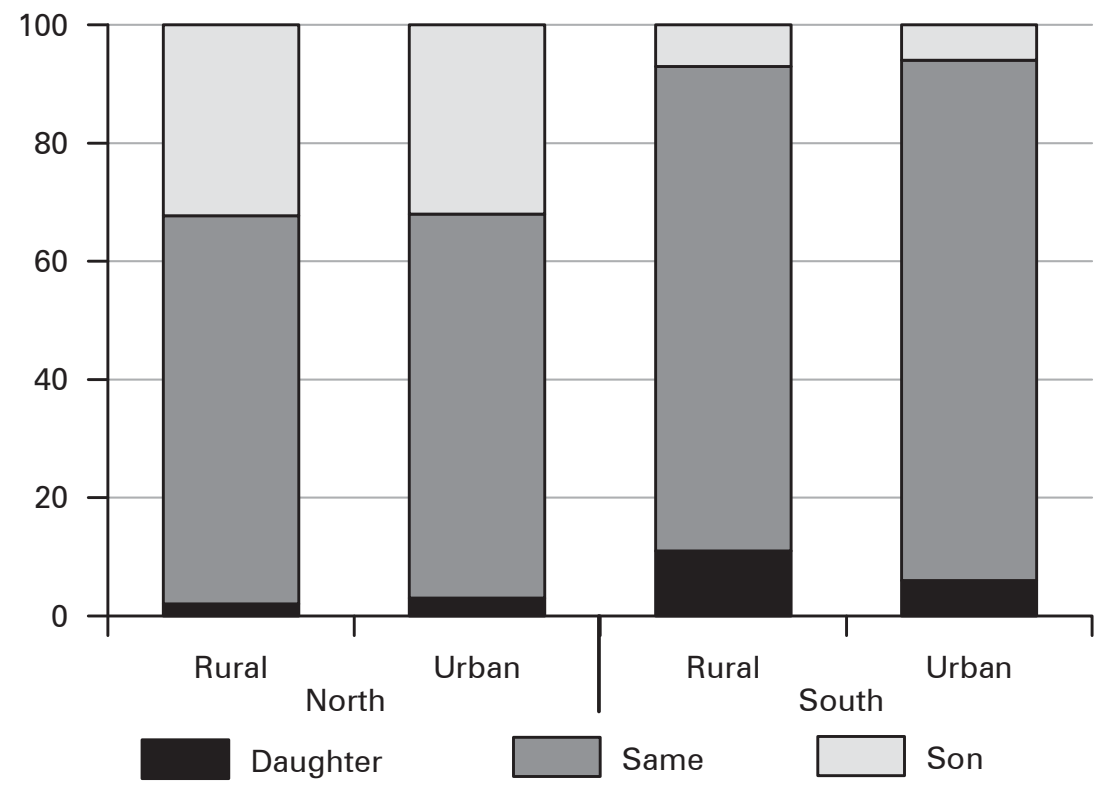

Source: VOC-data India, N = 1,173

posed. The four columns in the left part of Figure 3 prove that significantly more respondents attribute a relatively higher benefit level to sons in north India than in south India. The percentage is highest in the urban sample of north India (41 percent) and lowest in the urban south Indian sample (16 percent). It is remarkable that the lower prevalence of higher son benefit in south India does not result in a higher percentage of balanced benefit expectations but in a higher daughter benefit: 39 percent of the rural and even 50 percent of the urban respondents in south India attribute higher financial assistance and old-age support to daughters. This even exceeds the percentage of mothers who expect higher son benefits. The widespread expectation of higher benefits linked to a daughter is in line with the relatively high percentage of daughter preference found in our southern sample (Fig. 2).

The higher benefit of sons to care for their elderly parents (financially) in north India is complemented by their social-normative benefit (not shown in Fig. 3): It is rated highest among mothers in urban north India $(\mathrm{M}=3.2$ ) and lowest in urban south India ( $M=2.0$ ). Both rural sub-samples range in between ( $M=2.7)$. The mean differences are significant $(p<0.001)$. Altogether, the overall son-benefit is found to be lowest in our urban south Indian sample and the highest in urban north India.

Regional differences are less pronounced in terms of child related costs but still match the sex preference pattern (see right four columns in Fig. 3). The vast majority of respondents in south India make no distinction between sons and daughters with respect to monetary expenses: 75 percent (rural) and as many as 83 percent (urban) of the respondents in south India assess both cost the same, coinciding with 
Fig. 3: Region-specific costs and benefits attached to children (in percent)

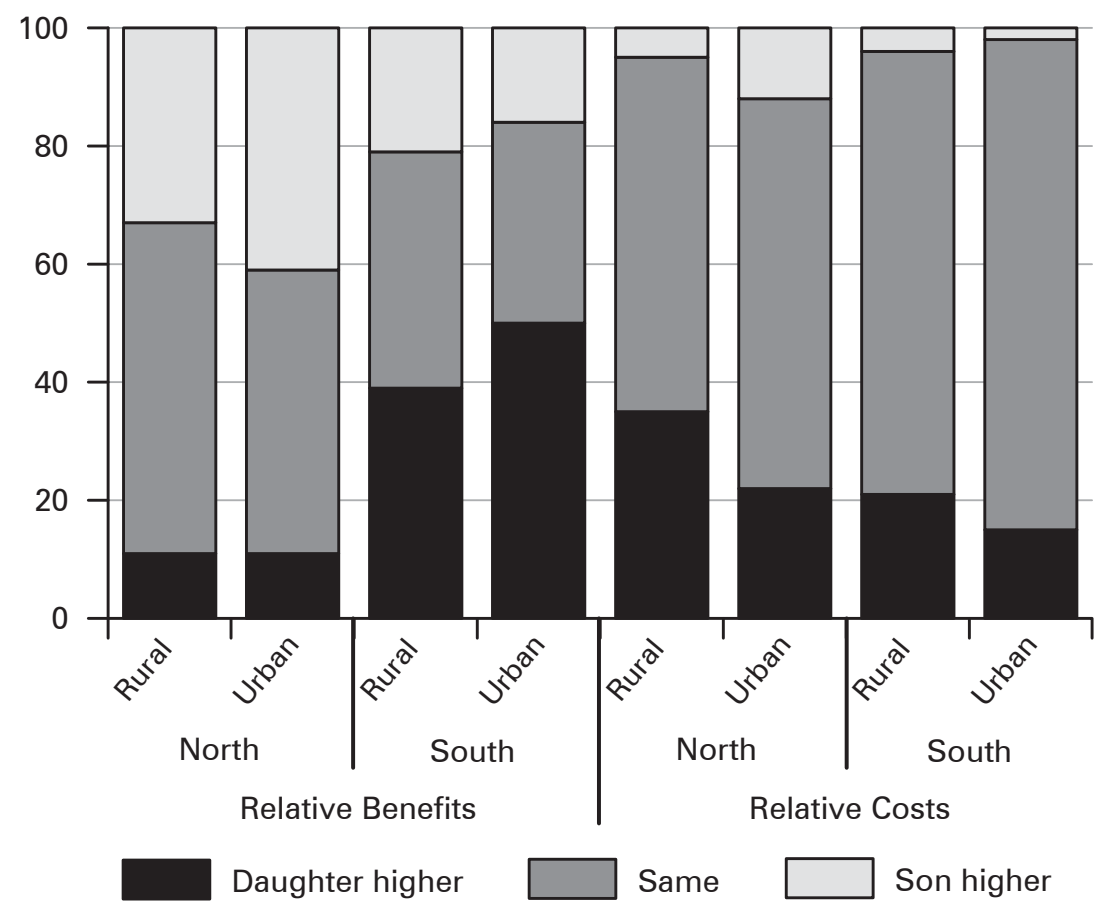

Source: VOC-data India, $\mathrm{N}=1,173$

their widespread lack of sex preference. In north India, equal costs are reported most often as well - by around two thirds. Higher costs attached to daughters form the second largest group in every considered region but with the highest share among village mothers in north India (35 percent). This may point to high dowry payments in relation to fairly limited financial resources.

Based on the bivariate observation, we can draw a preliminary conclusion. Whereas females' relatively high economic and instrumental value in south India together with predominately equal costs attributed to sons and daughters may produce a high rate of those who have no sex preference at all, in north India the stronger son preference may be triggered by high benefits related to sons accompanied by high costs related to daughters. Comparing rural and urban locations, no systematic variations are found. These initial comparisons of group-means only provide a rough picture and supply no information on associations at the individual level. The subsequent multivariate test provides an in-depth analysis of the internal structure considering additional potential predictors. 


\subsection{Multivariate Findings}

The theoretical model was applied to the data by SEM. In the full baseline model (not shown) the respondent's degree of religiosity is found to be of marginal explanatory power which contradicts our hypotheses ( $\mathrm{H} 4$ and $\mathrm{H} 9$ ). Religiosity is related neither to sex-specific child-related costs nor to benefits. Less prevalent son preference among south Indian respondents does not stem from their lower religiosity. Instead, mean values of religiosity are found to be high across the regional sub-samples with minor differences ( $\mathrm{M}=$ from 3.3 to 3.5 ). As a consequence, we exclude religiosity from the final model which is illustrated in Figure 4.

Fig. 4: Explanation of son preference (final model)

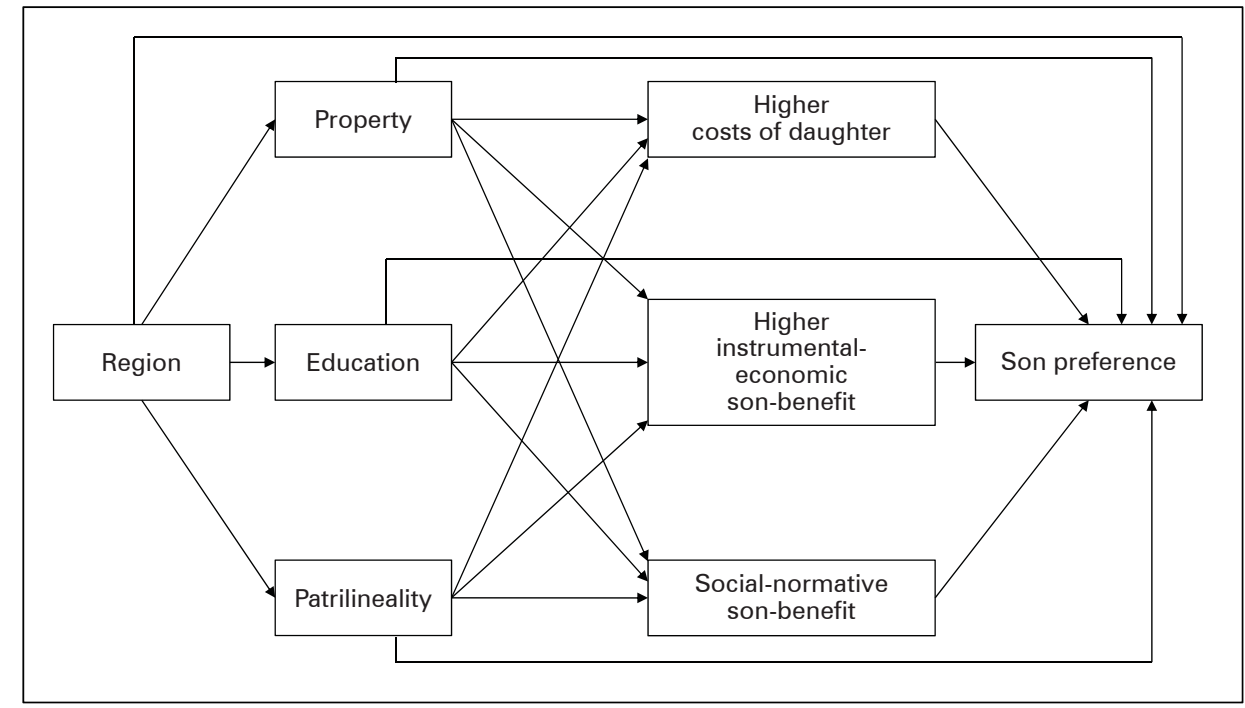

Source: Own design

In Table 1 the standardised coefficients and the z-statistics of the final model are provided. We report all direct effects and the indirect effects related to the respondent's regional residence. Two common fit indices are provided to assess how good the final model matches to our data: $\mathrm{CFI}=0.970$, $\mathrm{RMSEA}=0.052$. Following the cutting points suggested by $\mathrm{Hu}$ and Bentler (1999) values higher than 0.95 for $\mathrm{CFI}$ and lower than 0.06 for RMSEA indicate a relatively good fit. Accordingly, our hypothesised model is found to be of reasonable quality.

\section{Mediation effect}

Whereas the bivariate test has already identified the hypothesised north-south difference in the prevalence of son preference (Fig. 2), the multivariate model adds some enlightening information: The overall region effect splits up in significant di- 
rect and significant indirect effects. The indirect effects of respondent's residence on the son preference are provided in section IV of Table 1: Mediated by regionspecific background variables and the cost-benefit structure of children respondents in north urban $(-0.165)$, south rural $(-0.140)$, and south urban India $(-0.199)$ have significant lower rates of son preference than mothers in north rural India (reference group). Basically, this confirms our hypothesis (H2).

The region effect is, however, only partly mediated because significant direct effects remain in existence (section I, Table 1): Corresponding to the indirect effects, south rural $(-0.232)$ and south urban respondents $(-0.210)$ are revealed as having a lower rate of son preference than respondents in north rural India (reference group). But remarkably, when controlling for the indirect paths, respondents in north urban India show the most pronounced son preference. The combination of their positive direct $(0.159)$ and their negative indirect effect $(-0.165)$ on son preference obviously levels out and thus, was masked in the bivariate test. These findings suggest regionspecific characteristics beyond the socioeconomic status and the kinship structure to be responsible for north urban respondents' higher probability of son preference compared to their southern and even rural counterparts. In general, as direct region effects diminish but do not disappear in the mediation-model, unobserved factors or mechanisms relevant for son preference exert influence.

\section{Composition effects}

Still, a substantial part of the variation in son preference over the regions stems from region-specific distributions of the respondents' characteristics considered - yet, some of the effects are unexpected or were not anticipated. For a detailed look we focus on section II in Table 1. Respondents in the urban sample in north India turn out to be upper class members. They live in the most affluent households (0.520) and are the highest educated (0.895). Respondents in south India are middle educated with no substantial rural-urban differences $(0.475$ for rural and 0.564 for urban respondents) and northern village respondents are least educated (reference group).The latter live in the most pronounced patrilineal environment as significantly lower levels of patrilineal strength are found for the other three subsamples: -0.374 for north urban, -0.452 for south rural, and -0.486 for south urban respondents.

These findings call for a refinement of our composition hypotheses: There is no simple north-south gap but a rather complex rural-urban distinction has to been added: Whereas in south India, urban and rural respondents are fairly alike, we observe a great difference in north India. In line with our hypotheses, villagers in north India have a lower socioeconomic status $(\mathrm{H} 3)$ and stronger patrilineality than respondents in south India (H4). This, however, does not apply for urban respondents in north India: In contrast to their rural counterparts, they have a higher socioeconomic status and do not differ in terms of patrilineality from respondents in south India.

Nevertheless, the regional profiles contribute to the explanation of the regional variations in son preference. The region-specific levels of affluence and education 
are linked to son preference although somewhat different from our hypotheses. Whereas affluence is found to be positively related to son preference, education is negatively related. This is evident for both variables' direct impact (section I, Table 1: 0.083 for property and -0.148 for education) but also applies for their indirect impact via the individually held benefit-and cost-expectations (see the following section).

\section{Benefit-cost effects}

If we focus on the explanatory contribution of the benefits and costs attributed to children, we learn first that they significantly predict son preference in the expected way (section I, Table 1): Respondents are more likely to prefer a son if they perceive relative higher daughter-costs $(0.186)$, relative higher instrumental-economic son-benefits (0.128), and higher social-normative son-benefit (0.144). This is in line with hypotheses ( $\mathrm{H} 5$ and $\mathrm{H} 6$ ). At the same time, one of the key propositions of the VOC-approach is confirmed: The preference for children of a certain sex is at least partly based on a consideration of the benefits and costs expected from both sexes. If (potential) parents perceive a higher net-benefit of a son, they wish to have a son instead of a daughter. This is reasonable in the light of the limited pool of (financial and time) resources people have and the assumption that they tend to spend the resources with the objective of optimising personal profit.

However, the socioeconomic background variables show a fairly inconsistent prediction of the child-related costs and benefits and the sociocultural variables do not even add to their explanation at all (section III, Table 1). Neither child-related costs nor benefits are related to the degree of patrilineality (and religiosity, which has been already omitted from the final model). This finally disproves hypothesis (H9).

If we inspect the socioeconomic variables in more detail, we discover that respondents from affluent families are more likely to expect that daughters cost more than sons (0.143). This confirms the hypothesis ( $\mathrm{H} 8)$ which was informed by the assumption of large dowry payments in upper class families. At the same time, an unexpected finding emerges: Upper class respondents expect higher son-benefits of both kinds: instrumental-economic (0.079) and social-normative (0.199). This disproves hypothesis $(\mathrm{H} 7)$ which was basically built on the idea of lower reliance on child-related (old-age) support and a less adherence to religiously-motivated benefits provided by sons among affluent families. The finding might indicate that we have overestimated the greater independence of upper class families on child related benefits and the related levelling effect on the gender gap. The unexpected higher son benefits in the upper class may be caused by persistently strong patriarchal norms. They may, in turn, imply that women are more likely to be excluded from labour market and are subordinate in religious ceremonies like the funeral. In total, the level of affluence has a positive effect on son preference which challenges the few studies that proved minor but negative wealth effects on son preference (Bhat/Zavier 2003; Gaudin 2011; Pande/Astone 2007). 
Tab. 1: Explanation of son preference (regression coefficients based on SEM)

\begin{tabular}{|c|c|c|}
\hline & Standard Coefficient & z-score (sig.) \\
\hline \multicolumn{3}{|c|}{ Direct effects on son preference (probit) } \\
\hline \multicolumn{3}{|l|}{ Region (ref.: north-rural): } \\
\hline north-urban & 0.159 & $2.192^{*}$ \\
\hline south-rural & -0.232 & $-3.596^{* *}$ \\
\hline south-urban & -0.210 & $-2.997^{*}$ \\
\hline Property & 0.083 & $1.821^{+}$ \\
\hline Education & -0.148 & $-2.170^{*}$ \\
\hline Patrilineality & 0.115 & $2.146^{*}$ \\
\hline Higher costs of daughter & 0.186 & $3.287^{* *}$ \\
\hline Higher instrumental-economic son-benefit & 0.128 & $2.422 *$ \\
\hline Social-normative son-benefit & 0.144 & $2.884^{* *}$ \\
\hline \multicolumn{3}{|c|}{ Direct effects on socioeconomic and sociocultural variables } \\
\hline \multicolumn{3}{|l|}{ Property (linear) } \\
\hline \multicolumn{3}{|l|}{ Region (ref.: north-rural): } \\
\hline north-urban & 0.520 & $15.795^{* * *}$ \\
\hline south-rural & 0.101 & $3.295^{* *}$ \\
\hline south-urban & -0.131 & $-3.333^{* *}$ \\
\hline \multicolumn{3}{|l|}{ Education (linear) } \\
\hline \multicolumn{3}{|l|}{ Region (ref.: north-rural): } \\
\hline north-urban & 0.895 & $22.981 * * *$ \\
\hline south-rural & 0.475 & $13.228 * * *$ \\
\hline south-urban & 0.564 & $15.456 * * *$ \\
\hline \multicolumn{3}{|l|}{ Patrilineality (linear) } \\
\hline \multicolumn{3}{|l|}{ Region (ref.: north-rural): } \\
\hline north-urban & -0.374 & $-9.278^{* * *}$ \\
\hline south-rural & -0.452 & $-11.851 * * *$ \\
\hline south-urban & -0.486 & $-12.804^{* * *}$ \\
\hline \multicolumn{3}{|c|}{ III Direct effects on cost- and benefit variables } \\
\hline \multicolumn{3}{|c|}{ Higher costs of daughter (probit) } \\
\hline Property & 0.143 & $3.236^{* *}$ \\
\hline Education & -0.291 & $-5.675^{* *}$ \\
\hline Patrilineality & -0.019 & -0.414 \\
\hline \multicolumn{3}{|c|}{ Higher instrumental-economic son-benefit (probit) } \\
\hline Property & 0.079 & $1.767^{+}$ \\
\hline Education & -0.045 & -0.895 \\
\hline Patrilineality & -0.023 & -0.489 \\
\hline
\end{tabular}


Tab. 1: Continuation

\begin{tabular}{lcc}
\hline & Standard Coefficient & z-score (sig.) \\
\hline Social-normative son-benefit (linear) & & \\
Property & 0.199 & $5.220^{* * *}$ \\
Education & -0.128 & $-3.174^{* *}$ \\
Patrilineality & -0.019 & 0.577 \\
IV Indirect Effects on son preference (probit) & & \\
Region (ref.: north-rural): & -0.165 & $-2.764^{* *}$ \\
north-urban & -0.140 & $-3.527^{* * *}$ \\
south-rural & -0.199 & $-4.083^{* * *}$ \\
south-urban & & 0.330 \\
\hline$R^{2}$ Son preference & & $63.690(13)^{* * *}$ \\
Chi ${ }^{2}$ (df) & & $0.052 / 0.970$ \\
RMSEA / CFI & & \\
\hline
\end{tabular}

Note: WLSMV estimation. ${ }^{* *}<.001 ;{ }^{*}<.01 ;{ }^{*}<.05 ;+<.1$. Controlled for age, number of sons, and interrelations between the cost and benefits aspects and between the socioeconomic and sociocultural variables.

Source: VOC- data India. $N=1,173$

In line with previous findings, women's education has an overall negative effect on son preference (Bhat/Zavier 2003; Pande/Astone 2007). Our findings add to the existing research because they demonstrate that the negative effect is partly mediated by sex-specific costs and benefits: The higher the education, the lower the probability of stating higher daughter-costs $(-0.291)$ which is found to promote son preference. This finding challenges hypothesis (H8). It suggests that women's education is less an indication of socioeconomic class and thus linked to the need and amount of dowry (as we have assumed). Instead, high education obviously reflects less gendered investment strategies in children and the same educational aspirations for any offspring regardless of the sex. It might indicate a more egalitarian environment in which women enjoy higher status and are less constrained by rigid patrilineal and patriarchal norms. This might also be applicable to the finding that social-normative reasons for sons become less important with better education of mothers (-0.128). Sex-specific attitudes and attributions might be less dominant among well educated women and thus, implying wider role definitions and opportunities for them. 


\section{Discussion}

In this article, we aimed to explain son preference in India and its variations across the country. State-wise juvenile sex-ratios and individual sex preferences based on the Indian NFHS strongly suggest a persistent north-south gradient in son preference. This national pattern was confirmed by our two Indian sub-samples which are exemplary for north and south-east India (compare Fig. 2).

To shed light on the underlying mechanisms that may be responsible for these variations, we proposed a theoretical model following the VOC-approach. As implicitly done by most of the research on this issue, we explicitly relied on a costbenefit rationale behind the sex preference. We argued that son preference reflects a cost-benefit balance in favour of sons which in turn is triggered by a specific combination of individual characteristics. Hence, extending the previous research, the major purpose of our analysis was to provide empirical evidence for the explanatory power of the sex-specific costs and benefits and the region-specific distribution of relevant socioeconomic and cultural factors. The complex theoretical model was translated by SEM that is most adequate to disentangle direct and indirect effects. A unique opportunity was provided by the VOC-data because they cover attitudes towards the costs and benefits separately for daughters and sons. Moreover, data were gathered in two distinct regions of India.

Some hypotheses were confirmed whereas others were disproved: Son preference was indeed more probable among mothers with higher expectations of son-benefits and daughters-costs. This significantly adds to the empirical state of research as, to our knowledge, this has not been demonstrated by any other study. However, respondents' affluence, educational level, patrilineal contact patterns, and their degree of religiosity hardly affected their cost-benefit-structure in the expected way. In fact, the direct effects of these background variables on son preference dominated. The almost complete insignificance of cultural aspects is one of the most puzzling findings because almost all work in this field underlines the patrilineal structures and the Hindu Code as vital determinants for the pronounced son preference in India.

At this point it cannot be ruled out that data limitations account for the small or even missing effects, at least to some extent. This especially applies to the measurements of the benefit-concept of children. The social-normative facet is underrepresented first, because it is restricted to motivations based on religious grounds. It ignores children's alternative value such as for the intergenerational transfer of the family's wealth, the continuance of social approval and status (even beyond parents' death), and thus the reproduction of the social order by the offspring. Second, it is not measured separately for daughters and sons. The indicators are thus suboptimal and do not pay enough attention to Indian's specifics. This shortcoming results from the fact that the Indian VOC-data were collected within a larger international project with a somewhat different focus, namely the provision of countryequivalent data and the exploration of the overall fertility instead of gender biased preferences. This might also adversely affect the coverage of the respondents' cultural background. The strength of the patrilineality - as a very complex concept - 
was only indicated by a significant but single aspect: the intergenerational contact pattern. Marriage and inheritance practices are also highly relevant facets of the kinship regime but were not available in the present data.

One explanation for the surprising insignificance of religiosity is related to its attitudinal indicator which poorly differentiates between the respondents. As argued elsewhere (Glock 1954), it is more effective to add religiously-motivated behaviour such as attendance at religious ceremonies. This might be less sensitive towards response biases such as social desirability. Given these shortcomings, our findings should be interpreted with caution. The effects might be underestimated. Validating the cost-benefit argument based on a broader and more comprehensive array of measurements is strongly recommended. At the same time, however, the theoretical perspective on son preference needs to be revisited.

We come to a similar conclusion when we review the composition effects. Prominent variations in son preference across the regional sub-samples emerged. As expected, a significant part of the variance could be interpreted in terms of socioeconomic and cultural specifics, but a substantial proportion remained unexplained. Highly remarkable is the most pronounced son preference in the north-rural sample when controlling for the background variables considered. A more detailed inspection reveals that the majority of these respondents are married to husbands who work in well-paid positions, mainly as white collar workers (51 percent) and in the public or financial sector (59 percent). We observe a quite homogeneous urban sample which is very modern and affluent in socioeconomic terms but adheres to traditional, sex-segregated attitudes and norms, especially when compared to their southern counterparts. On the one hand, facets of costs and benefits that were not adequately considered in our study might help to dissolve the strong direct effects that emerged. On the other hand, the substantial amount of unexplained variance in son preference $\left(R^{2}=0.33\right)$ calls for a critical review of the widely held set of arguments which are cited to produce son preference. For a satisfactory explanation, future research should pay more attention to mechanisms beyond the cost-benefit argument.

In this respect it might be fruitful to consider son preference separately for men and women and to discuss the marital decision making process in case of spouses' disagreement. One major limitation of our sample is its restriction to mothers. The high percentage of respondents without any sex preference shown might be overestimated since no men or childless women were available. It is reasonable to assume that male family members are more concerned about lineage related benefits like the continuation of the family and thus have a stronger interest in male offspring. Moreover, patriarchal structures imply that men are more powerful and therefore in a better position to assert their interests in terms of family planning. Thus, the exploration of sex-specific mechanisms and dyadic dynamics might add to existing knowledge. This also applies to the analysis of the development of preferences along the life course. A childless woman's preference may change after her transition to motherhood and following every subsequent birth as an adaptation either to personal experiences with children of a certain sex (as a kind of correction) or to the present sex-composition (as an attempt to establish consistency). 
A final issue is related to the measurement of son preference: In general, sex preference is a strong motivator for sex-specific fertile behaviour which finally manifests in a more or less corresponding sex-composition of the children. But because of, inter alia, unequal access to sex diagnosis technology and abortion or potential spousal disagreement on preferences, individual sex preferences and the resulting behaviour do not necessarily correspond. Thus, attitudinal and behavioural measures are interrelated but distinct aspects of sex preference. Whereas the attitudinal measure may be subjected to response biases due to social desirability during the interview the behavioural measure may be biased due to unequal abilities to achieve individual sex preferences. To improve the understanding of sex preference and sex-ratios, we thus suggest an extension of the present research by exploring the behavioural side and the link between both.

\section{Acknowledgment}

This study is part of the research project "Value of Children, Fertility and Intergenerational Relationships in Cross-National Comparison". The principal investigators are Bernhard Nauck (Chemnitz University of Technology, Germany) and Gisela Trommsdorff (University of Konstanz, Germany). The Indian collaborators in the study are Ramesh Mishra (Banaras Hindu University, Varanasi, India) and Arun Tipandjan (International Centre for Psychological Counseling and Social Research, Puducherry, India) who organised the fieldwork. The project was supported by the German Research Foundation (DFG). We would like to thank two anonymous reviewers for their helpful suggestions.

\section{References}

Agarwal, Bina 1988: Who sows? Who reaps? Women and land rights in India. In: The Journal of Peasant Studies 15,4: 531-581 [doi: 10.1080/03066158808438377].

Anderson, Siwan 2003: Why dowry payments declined with modernization in Europe but are rising in India. In: Journal of Political Economy 111,2: 269-310 [doi: 10.1086/367679].

Anderson, Siwan 2007: The economics of dowry and brideprice. In: The Journal of Economic Perspectives 21,4: 151-174 [doi: 10.1257/jep.21.4.151].

Arnold, Fred; Choe, Minja Kim; Roy, T. K. 1998: Son Preference, the Family-Building Process and Child Mortality in India. In: Population Studies 52,3: 301-315 [doi: 10.1080/0032472031000150486].

Basu, Alaka Ma/wade 1999: Fertility decline and increasing gender imbalance in India, including a possible South Indian turnaround. In: Development and Change 30,2: 237263 [doi: 10.1111/1467-7660.00116].

Becker, Gary Stanley 1996: Eine ökonomische Analyse der Familie. In: Becker, Gary Stanley (Ed.): Familie, Gesellschaft und Politik: Die ökonomische Perspektive. Tübingen: Mohr Siebeck GmbH \& Co. KG: 101-116.

Behrman, Jere Richard 1988: Intrahousehold allocation of nutrients in rural India: Are boys favored? Do parents exhibit inequality aversion? In: Oxford Economic Papers 40,1: 32-54. 
Bhat, P. N. Mari; Zavier, A. J. Francis 2003: Fertility Decline and Gender Bias in Northern India. In: Demography 40,4: 637-657 [doi: 10.2307/1515201].

Bhaumik, Saurav 2012: Declining Sex Ratio in India and Its Impact with Special Reference to Punjab, Rajasthan and Haryana [URL: http://papers.ssrn.com/sol3/papers. cfm?abstract_id=2037847, 27.11.2012].

Borooah, Vani K. 2004: Gender bias among children in India in their diet and immunisation against disease. In: Social Science \& Medicine 58,9: 1719-1731 [doi: 10.1016/ S0277-9536(03)00342-3]

Cain, Mead 1986: The Consequences of reproductive failure: Dependence, mobility, and mortality among the elderly of rural south Asia. In: Population Studies 40,3: 375-388 [doi: 10.1080/0032472031000142306].

Caldwell, John C.; Reddy, P. Hemachandra; Caldwell, Pat 1982: The causes of demographic change in rural South India: A micro approach. In: Population and Development Review 4,4: 689-727 [doi: 10.2307/1972469].

Caldwell, John C.; Reddy, P. Hemachandra; Caldwell, Pat 1984: The determinants of family structure in rural South India. In: Journal of Marriage and the Family 46,1: 215229 [doi: 10.2307/351879]

Chamarbagwala, Rubiana 2011: Sibling composition and selective gender-based survival bias. In: Journal of Population Economics 24,3: 935-955 [doi: 10.1007/s00148010-0314-z].

Chen, Susan E.; Bhagowalia, Priya; Shively, Gerald 2011: Input Choices in Agriculture: Is There A Gender Bias? In: World Development 39,4: 561-568 [doi: 10.1016/j.worlddev.2010.09.012].

Clark, Shelley 2000: Son preference and sex composition of children: Evidence from India. In: Demography 37,1: 95-108 [doi: 10.2307/2648099].

Dalmia, Sonia; Lawrence, Pareena G. 2005: The institution of dowry in India: Why it continues to prevail. In: The Journal of Developing Areas 38,2: 71-93 [doi: 10.1353/ jda.2005.0018]

Das Gupta, Monica; Bhat, P.N. Mari 1997: Fertility decline and increased manifestation of sex bias in India. In: Population Studies 51,3: 307-315 [doi: 10.1080/ 0032472031000150076].

Das Gupta, Monica et al. 2003: Why is son preference so persistent in East and South Asia? A cross-country study of China, India and the Republic of Korea. In: The Journal of Development Studies 40,2: 153-187 [doi: 10.1080/00220380412331293807].

Diamond-Smith, Nadia; Luke, Nancy; McGarvey, Stephen 2008: 'Too many girls, too much dowry': Son preference and daughter aversion in rural Tamil Nadu, India. In: Culture, Health \& Sexuality 10,7: 697-708 [doi: 10.1080/13691050802061665].

Dyson, Tim; Moore, Mick 1983: On kinship structure, female autonomy, and demographic behavior in India. In: Population and Development Review 9,1: 35-60 [doi: 10.2307/1972894].

Friedman, Debra; Hechter, Michael; Kanazawa, Satoshi 2007: A Theory of the Value of Children. In: Demography 31,1: 375-401 [doi: 10.2307/2061749].

Gaudin, Sylvestre 2011: Son Preference in Indian Families: Absolute Versus Relative Wealth Effects. In: Demography 48,1-28 [doi: 10.1007/s13524-010-0006-z].

Glock, Charles Y. 1954: Toward a typology of religious orientation. New York: Bureau of Applied Social Research: Columbia University. 
Goodkind, Danie/ 1996: On substituting sex preference strategies in East Asia: Does prenatal sex selection reduce postnatal discrimination? In: Population and Development Review 22,1: 111-125 [doi: 10.2307/2137689].

Government of India 2011: Census of India 2011.

Hu, Li-tze; Bentler, Peter M. 1999: Cutoff criteria for fit indexes in covariance structure analysis: Conventional criteria versus new alternatives. In: Structural Equation Modeling: A Multidisciplinary Journal 6,1: 1-55 [doi: 10.1080/10705519909540118].

International Institute for Population Sciences (IIPS); Macro International 2007: National Family Health Survey (NFHS-3), 2005-06: India. Mumbai: IIPS

Jaggi, Tonushree 2001: The economics of dowry: Causes and effects of an Indian tradition. In: Journal of Economics 4: 1-19.

Jejeebhoy, Shireen J.; Sathar, Zeba A. 2001: Women's autonomy in India and Pakistan: the influence of religion and region. In: Population and Development Review 27,4: 687 712 [doi: 10.1111/j.1728-4457.2001.00687.x].

Kagitcibasi, Cigdem 1982: Changing value of children in Turkey. Honolulu, Hawaii: EastWest Center.

Klaus, Daniela 2010: Changing Value of Children and Fertility Transition in Turkey. In: Journal of Comparative Family Studies 41,5: 799-816.

Leibenstein, Harvey 1975: The Economic theory of fertility decline. In: Quarterly Journal of Economics 89,1: 1-31 [doi: 10.2307/1881706].

Liefbroer, Aart C. 2005: The Impact of perceived costs and rewards of childbearing on entry into parenthood: Evidence from a panel study. In: European Journal of Population 21,4: 367-391 [doi: 10.1007/s10680-005-2610-y].

Miller, Barbara D. 1981: The Endangered Sex: Neglect of Female Children in Rural North India. Ithaca, NY: Cornell University Press.

Mutharayappa, Rangamut et al. 1997: Is son preference slowing down India's transition to low fertility? Mumbai: International Institute for Population Sciences.

Nasir, Rosina; Kalla, Aloke K. 2006: Kinship system, fertility and son preference among the muslims: A review. In: Anthropologist 8,4: 275-281.

Nauck, Bernhard 2001: Der Wert von Kindern für ihre Eltern. In: Kölner Zeitschrift für Soziologie und Sozialpsychologie 53,3: 407-435 [doi: 10.1007/s11577-001-0073-7].

Nauck, Bernhard 2007: Value of children and the framing of fertility: Results from a cross-cultural comparative survey in 10 societies. In: European Sociological Review 23,5: 615-629 [doi: 10.1093/esr/jcm028].

Ormel, Johan et al. 1999: Subjective well-being and social production functions. In: Social Indicators Research 46,1: 61-90 [doi: 10.1023/A:1006907811502].

Oster, Emily 2009: Proximate sources of population sex imbalance in India. In: Demography 46,2: 325-339 [doi: 10.1353/dem.0.0055].

Pande, Rohini P. 2003: Selective gender differences in childhood nutrition and immunization in rural India: The role of siblings. In: Demography 40,3: 395-418 [doi: 10.1353/ dem.2003.0029].

Pande, Rohini P.; Astone, Nan Marie 2007: Explaining son preference in rural India: the independent role of structural versus individual factors. In: Population Research and Policy Review 26,1: 1-29 [doi: 10.1007/s11113-006-9017-2].

Probst, Wiebke 2009: The missing women phenomenon in India: Causes and effects. In: Journal of Young Investigators 19,17: 1-10. 
Rao, Vijayendra 1993: The rising price of husbands: A hedonic analysis of dowry increases in rural India. In: Journal of Political Economy 101,4: 666-677.

Reserve Bank of India 2012: Handbook of Statistics on the Indian Economics. Mumbai: India Printing Works.

Rosenzweig, Mark R.; Schultz, T. Paul 1982: Market opportunities, genetic endowments, and intrafamily resource distribution: Child survival in rural India. In: The American Economic Review 72,4: 803-815.

Sen, Amartya 2005: The argumentative Indian: Writings on Indian culture, history and identity. London: Penguin.

Sengupta, Manisha; Agree, Emily M. 2002: Gender and disability among older adults in North and South India: differences associated with coresidence and marriage. In: Journal of Cross-Cultural Gerontology 17,4: 313-336 [doi: 10.1023/A:1023079219538].

Simon, Herbert Alexander 1982: Models of bounded rationality: Empirically grounded economic reason. MIT press.

Singh, J. P. 2005: The contemporary Indian family. In: Adams, Bernd N.; Trost, Jan (Eds.): Handbook of world families. Thousand Oaks, California: Sage Publications: 129-166 [doi: 10.4135/9781412975957].

Srinivasan, Sharada 2005: Daughters or dowries? The changing nature of dowry practices in South India. In: World Development 33,4: 593-615 [doi: 10.1016/j.worlddev.2004.12.003].

The Economist 2012 [URL: hhtp://www.economist.com/content/indian-summary, 30. April 2014].

Trommsdorff, Gisela; Nauck, Bernhard 2005: The value of children in cross-cultural perspective. Lengerich: Pabst Science Publishers.

Trommsdorff, Gisela; Nauck, Bernhard 2010: Value of children: A concept for better understanding crosscultural variations in fertility behavior and intergenerational relationships. In: Journal of Cross-Cultural Psychology 41: 637-651 [doi: 10.1177/ 0022022110373335].

UNFPA 2012: Sex imbalances at birth: Current trends, consequences and policy implications. Bangkok: UNFPA.

Vlasoff, Carol 1990: The value of sons in Indian village: How widows see it. In: Population Studies 44,1: 5-20 [doi: 10.1080/0032472031000144356].

Dr. Daniela Klaus (凹). German Centre of Gerontology. 12101 Berlin, Germany.

E-Mail: daniela.klaus@dza.de

URL: http://www.dza.de/en/about-the-dza/staff/klaus.html

Dr. Arun Tipandjan. International Center for Psychological Counseling \& Social Research. 605011 Puducherry, India. E-Mail: aruneps73@gmail.com

URL: www.icpcsr.org 


\section{Comparative Population Studies}

WWW.comparativepopulationstudies.de

ISSN: 1869-8980 (Print) - 1869-8999 (Internet)

Published by / Herausgegeben von

Prof. Dr. Norbert F. Schneider

Federal Institute for Population Research

D-65180 Wiesbaden / Germany

\section{Managing Editor /}

Verantwortlicher Redakteur

Frank Swiaczny

\section{Assistant Managing Editor /}

\section{Stellvertretende Redakteurin}

Katrin Schiefer

\section{Copy Editor (German) /}

Lektorat (deutsch)

Dr. Evelyn Grünheid

\section{Layout / Satz}

Beatriz Feiler-Fuchs

E-mail:cpos@bib.bund.de

\section{Scientific Advisory Board /}

Wissenschaftlicher Beirat

Paul Gans (Mannheim)

Johannes Huinink (Bremen)

Michaela Kreyenfeld (Rostock)

Marc Luy (Wien)

Clara H. Mulder (Groningen)

Notburga Ott (Bochum)

Peter Preisendörfer (Mainz)

Zsolt Spéder (Budapest)
Board of Reviewers / Gutachterbeirat Martin Abraham (Erlangen)

Laura Bernardi (Lausanne)

Hansjörg Bucher (Bonn)

Claudia Diehl (Konstanz)

Andreas Diekmann (Zürich)

Gabriele Doblhammer-Reiter (Rostock)

Jürgen Dorbritz (Wiesbaden)

Anette Eva Fasang (Berlin)

E.-Jürgen Flöthmann (Bielefeld)

Alexia Fürnkranz-Prskawetz (Wien)

Beat Fux (Salzburg)

Joshua Goldstein (Berkeley)

Karsten Hank (Köln)

Sonja Haug (Regensburg)

Hill Kulu (Liverpool)

Aart C. Liefbroer (Den Haag)

Kurt Lüscher (Konstanz)

Emma Lundholm (Umeå)

Nadja Milewski (Rostock)

Dimiter Philipov (Wien)

Roland Rau (Rostock)

Tomáš Sobotka (Wien)

Jeroen Spijker (Barcelona)

Olivier Thévenon (Paris)

Helga de Valk (Brussel)

Heike Trappe (Rostock)

Michael Wagner (Köln) 